\title{
POLÍTICA DE FORMAÇÃO DE PROFESSORES: O PROGRAMA INSTITUCIONAL DE BOLSA DE INICIAÇÃO A DOCÊNCIA (PIBID) NO CURSO DE GEOGRAFIA/UFGD. TEORIA E PRÁTICA
}

\author{
Teacher Formation Policy: Institutional Program of the Iniciation to Teaching Grant (PIBID) in \\ the Course of Geografhy/UFGD. Theory and Practice
}

$\begin{array}{r}\text { Silvana de Abreu* } \\ \text { Adauto de Oliveira Souza** }\end{array}$
* Professora da UFGD - $\underline{\text { sabreu@ufgd.edu.br. }}$.
* Professor da UFGD - $\underline{\text { adautosouza@ufgd.edu.br. }}$.

Recebido em 06/08/2018. Aceito para publicação em 25/08/2018.

Versão online publicada em 20/11/2018 (http://seer.ufrgs.br/paraonde)

\begin{abstract}
Resumo: O PIBID foi proposto como uma política de formação de professores e cumpre a função de aproximar a Universidade das escolas públicas. A experiência que vivenciamos, desde 2009, no curso de Geografia/UFGD, com a implantação do PIBID, tem representado a incorporação, no âmbito das escolas de nível básico em Dourados (MS), de práticas formadoras para todos os participantes e tem envolvido os acadêmicos no cotidiano da relação ensino-aprendizagem nas escolas, permitindo trocas significativas para o desenvolvimento de atividades integradas de ensino, pesquisa e extensão contribuindo para a busca compartilhada de alternativas didáticas orientadas para práticas educativas que possibilitem articulação e dinamização do processo de ensino e aprendizagem.
\end{abstract}

Palavras-chave: PIBID; formação de professores; Ensino de Geografia.

Abstract: The PIBID was proposed as a policy of teacher training and fulfills the function of bringing the University closer to the public schools. The experience that we have experienced since 2009 in the Geography / UFGD course with the implementation of PIBID has represented the incorporation of training practices for all participants in the framework of the elementary schools in Dourados (MS) and has involved the academic In the daily life of the teaching-learning relationship in schools, allowrs significant exchanges for the development of integrated teaching, research and extension activities, contributing to the shared search for didactic alternatives oriented to educational practices that enable articulation and dynamization of the teaching and learning process.

Key words: PIBID; teacher training; Teaching Geography.

\section{Introdução}

Este trabalho é parte integrante do projeto de pesquisa "Ensino de Geografia na Educação Básica: uma avaliação do Programa Institucional de Bolsa de Iniciação à Docência (PIBID). Resultados e Proposições"1 cujo objetivo geral é avaliar o projeto PIBID do Curso de Geografia/UFGD, como política de valorização e de formação de professores - o impacto na formação - para o conjunto dos sujeitos envolvidos na execução do Programa, bem como elaboração de metodologia piloto para avaliação desta política educacional, no âmbito do Estado de Mato Grosso do Sul.

Assim, é importante destacar que a pesquisa e a construção metodológica tem se (re)construído

${ }^{1}$ Pesquisa financiada com recursos da FUNDECT/MS, sob a coordenação da Prof ${ }^{\underline{a}}$ Dra Silvana de Abreu. 
ao mesmo tempo, sobretudo porque os pesquisadores e pesquisadoras no projeto, em alguns casos, estão envolvidos com o PIBID Geografia como "coordenadores de área" e "supervisoras nas escolas", mas também como bolsistas e ex-bolsistas do Programa PIBID, participantes iniciantes em pesquisa pelo PIBIC-CNPq. Condição desafiadora que envolve o olhar sobre e do outro, mas que igualmente implica em olhar para sua/nossa prática.

Essa análise possibilita expressar a magnitude de ideias e teorias que devemos nos apropriar para avaliar uma política educacional como é o Programa Institucional de Bolsa de Iniciação à Docência (PIBID) ${ }^{2}$ e que não está sendo concebido como um programa de bolsas, mas como uma política de governo, de formação de professores e, recentemente, proposta como uma política de Estado, em consonância com as metas (Meta 15) do Plano Nacional de Educação (Lei 13.005/2014) para o decênio 2014/2024, mas que tem sido acompanhado com atenção, na medida em que a conjuntura política e institucional do Estado Brasileiro "neodesenvolvimentista" 3 e que se mostrava favorável a investimentos públicos em expansão do acesso a educação superior e na qualificação da formação de professores se modifica e perde solidez, com alterações aligeiradas e significativas na LDB e na Constituição Brasileira, desde abril de 2016, quando ocorreu o afastamento da presidenta Dilma Rousseff e posteriormente pela aprovação do seu impeachment, em movimento que vem sendo denunciado como de Golpe de Estado. ${ }^{4}$

Contudo, o fato é que mesmo dentro do Governo eleito de Dilma Rousseff, durante o ano de 2015, consolidou-se um significativo movimento nacional de defesa do PIBID, que ficaria conhecido como \#ficapibid e que mobilizou as universidades e escolas parceiras do PIBID, mas também pais e alunos que encontraram no Programa, em todas as áreas do conhecimento escolar, espaço para outras possibilidades e significação para a formação. O slogan "Brasil, Pátria Educadora" do PPA (2015-2018) certamente não combinou com os cortes no orçamento da educação instalados e o PIBID, que vinha sendo desenvolvido e em constante crescimento dentro da CAPES/MEC, desde 2009, entrou na fila de cortes do Governo Federal, tendo sido anunciado seu fim para julho de 2015.

A mobilização dos segmentos da educação superior e básica e também de parlamentares, foi significativa para segurar o processo de extinção do Programa, mas insuficiente para manter as condições orçamentárias de custeio no projeto institucional da UFGD (e das outras Instituições de Ensino Superior, participantes) e, evidentemente, no subprojeto de Geografia, com cortes que levaram seus gestores a dificuldades para realização de atividades pedagógicas e culturais programadas.

Além disso, viveu-se no ano de 2015 e 2016 o "stress" da reformulação do Programa, proposta pelo ainda Ministro da Educação Aloízio Mercadante, que não foi adiante com a proposta pela fragilidade e crise de governabilidade instalada, e que representava a transformação de uma política voltada para formação de professores em uma política de reforço escolar. ${ }^{5}$ Nesse movimento, o Programa da UFGD se viu na iminência de ser reformulado ${ }^{6}$ como condição de manutenção do PIBID como política educacional e institucional.

É certo dizer que o \#ficapibid foi e é um movimento de resistência e de contraposição a visão neoliberal que se instalaria para "dar conta" da crise fiscal e econômica alimentada pelo capital e pelos contrários ao governo (re)eleito, em objetivo explícito de fomentar a crise e levar a derrocada do Governo, o que veio a acontecer. Mas também é certo dizer que o processo de instabilidade gerado, riscos de cortes de bolsas, corte de recursos de custeio e investimento levaram a uma crise interna que rebateu no desenvolvimento das atividades nas escolas e também na capacidade de

\footnotetext{
2 Informações oficiais sobre o PIBID ver: http://www.capes.gov.br/educacao-basica/capespibid

3 Acerca dessa temática, consultar dentre outros: DINIZ (2013); FONSECA (2013). Ver também BOITO JR in: http://bibliotecadigital.fgv.br/dspace/bitstream/handle/10438/16866/Painel\%203\%20-

\%20Novo \%20Desenv\%20BR\%20-\%20Boito\%20-\%20Bases $\% 20$ Pol $\% 20$ Neodesenv $\% 20-\% 20$ PAPER.pdf?sequence=1 (acessado em 25/05/2017)

4 PRONER, C. et. al. (2016) e OLIVEIRA, T. B. (2016).

5 https://www.pensaraeducacaoempauta.com/da-formacao-de-professores-06-5-16 (ultimo acesso 31/05/2017)

6 Edital 46/CAPES/11/04/2016. Indicava a possibilidade de um novo PIBID sob outras bases e prioridades. Foi retirado pelo governo que assumiu a Capes e o MEC após o afastamento da Presidenta eleita, mas nada mudou do ponto de vista dos recursos e há profundo silêncio sobre o futuro (pós fevereiro de 2018) quando se enceram os projetos aprovados no último edital. Havia a perspectiva no Edital de prorrogação por mais quatro anos, mas ao que parece isso não deve ocorrer.
}

Para0nde!?, Porto Alegre, v.10, n.2, p.56-62, 2018. Edição Especial com artigos publicados originalmente na XII ENANPEGE http://seer.ufrgs.br/paraonde 
manter o interesse dos acadêmicos, que viram em outras experiências, como é o caso do PIBIC (Programa Institucional de Bolsas de Iniciação Científica) e do PET (Programa de Educação Tutoral), a possibilidade de manutenção da bolsa e sua condição de bolsista. Além disso, a incerteza sobre o tempo de bolsa que teriam, sob os horizontes "do novo edital para o novo Pibid" não eram atrativos para participação.

O PIBID de Geografia/UFGD, que chegou a ter mais de 10 alunos interessados/candidatos para disputa de vagas em 2014, passou a viver (junto com os demais subprojetos da UFGD) a abertura de editais de vagas e bolsas para os quais não apareciam candidatos, apesar de intenso processo de divulgação e campanha de participação no Programa. Para agravar a situação, bolsistas com 48 meses passaram a ser desligados.

Sem condições de preenchimento das vagas, pela baixa procura, a capacidade de intervenção nas escolas foi reduzida, com atendimento de menos turmas. Outro fenômeno que se viu acontecer foi a renovação de alunos bolsistas em sua quase totalidade. 0 segundo semestre de 2016 começaria com uma turma de doze bolsistas, dos quais 11 eram recém-ingressos no Programa e cursavam o primeiro ano de Geografia.

Nesse contexto, o PIBID de Geografia precisou reinventar-se no interior do próprio subprojeto; pensado para capacitar os acadêmicos e bolsistas para o domínio teórico-prático das linguagens artísticas, no processo de alfabetização geográfica e formação para a cidadania. A manutenção dessa condição requereu e vem requerendo a formação também em Geografia, ainda inicializada na própria graduação, e mudanças na participação menos protagonista e mais auxiliar nas escolas. Aspectos que se buscou superar em 2017, pelo amadurecimento dos acadêmicos no Curso de graduação e também no Programa e possibilidade de participação em intervenções diretas nas turmas de ensino fundamental e médio, abordando a temática "Mobilidade e Migrações".

Não é possível fazer a avaliação do PIBID de Geografia da UFGD e em qualquer instituição desse país sem considerar que os anos de 2015, 2016 e 2017 tem sido de resistência e organização dos sujeitos envolvidos, mas fundamentalmente de quebra no andamento e consolidação que o PIBID vinha fortalecendo, a ponto de entrar na pauta do Plano Nacinal de Educação (PNE), como apontado.

Veja-se fragmento da nota de repúdio do FORPIBD, em abril de 2016, ato contínuo a publicação do Edital 046/2016:

Com anuência do Ministro, Dr. Aloísio Mercadante, a postura assumida pela CAPES coloca a Agência na contramão da proposta de governo democrático, comprometido com a educação em todos os níveis. É grave o nível de desrespeito e incontornável o grau de indignação entre os educadores e educandos do PIBID e PIBID Diversidade frente a mais uma ameaça ao trabalho em andamento, orientado pelo compromisso firmado pelo governo de continuidade dos projetos aprovados nos Editais 061/2013 e 066/2013 até 2018, prorrogáveis por mais quatro anos. ${ }^{7}$

Nesse contexto, o PIBID tem se constituído em resistência e aprendizado de luta!

\section{O PIBID de Geografia/UFGD e a política de formação de professores: olhares concordantes e tensões}

O PIBID foi proposto como uma política governamental de formação de professores pelo Governo Federal, em 2007, e tem possibilitado a aproximação da Universidade com as escolas públicas. ${ }^{8}$

É fato! Há uma condição a priori e necessária para o Programa se instalar: a existência de um curso de licenciatura, de uma escola pública e de professores dispostos a integrarem o projeto.

\footnotetext{
7 Condição que se explicitaria em Nota de Repúdio encaminhado pelo Fórum Nacional do PIBID - FORPIBID. Ver Nota in: https://www.pensaraeducacaoempauta.com/repudio-06-5-16

8 Soczek (2011), avaliando políticas de formação de professores, entre elas o PIBID analisa como positivo considerar o espaço da escola e o aluno como elementos fundamentais para pensar os processos de formação em termos de alcance de seus objetivos.
}

Para0nde!?, Porto Alegre, v.10, n.2, p.56-62, 2018. Edição Especial com artigos publicados originalmente na XII ENANPEGE http://seer.ufrgs.br/paraonde 
Gatti, Barreto, e André (2014) ${ }^{9}$, em pesquisa qualitativa sistematizam informações prestadas por meio de questionário eletrônico e promovem uma avaliação horizontal do Programa. Nessa pesquisa, levantam trabalhos em eventos, teses e dissertações que analisam o PIBID e que tem uma vertente de estudos de caso, análises de metodologias. 0 estudo publicado (e aqui referenciado) tem a "Apresentação" de Jorge Almeida Guimarães (GATTI, BARRETO, e ANDRÉ, 2014, p.6), então Presidente da Coordenação de Aperfeiçoamento de Pessoal de Nível Superior - (CAPES), nos seguintes termos:

O PIBID, contudo, não é simplesmente um programa de bolsas. É uma proposta de incentivo e valorização do magistério e de aprimoramento do processo de formação de docentes para a educação básica. Os alunos de licenciatura exercem atividades pedagógicas em escolas públicas de educação básica, contribuindo para a integração entre teoria e prática, para a aproximação entre universidades e escolas e para a melhoria de qualidade da educação brasileira. Para assegurar os resultados educacionais, os bolsistas são orientados por coordenadores de área - docentes das licenciaturas - e por supervisores - docentes das escolas públicas onde exercem suas atividades. Com seu desenho, o PIBID é formação inicial para os alunos das licenciaturas; é, também, formação continuada para os professores das escolas públicas e para os professores das instituições de ensino superior participantes, abrindo-lhes amplas oportunidades de estudos, pesquisa e extensão. A ação dos Licenciandos e de seus orientadores tem o potencial de elevar a qualidade do trabalho nas escolas públicas e nas instituições formadoras. (grifo nosso)

Desafiador, o discurso do presidente da CAPES aponta para alguns aspectos importantes que envolvem o PIBID e rebatem diretamente na relação teoria e prática. Quais sejam: a valorização do magistério e aprimoramento na formação do professor para a educação básica; a formação continuada para os professores da escola básica e potencial de elevar a qualidade do trabalho nas escolas públicas, seja no ensino básico, seja nas instituições formadoras; e fundamentalmente melhorar a qualidade da educação no país. Em que medida o PIBID de Geografia tem respondido a essas condições e expectativas?

0 ponto de partida é afirmar que o Projeto de Geografia da UFGD é original e é significativo, em si, tanto para a sua análise específica, mas, sobretudo, para contribuição com a avaliação da política educacional (eficácia e eficiência) e a possibilidade de seu aprimoramento, manutenção e consolidação do Programa. ${ }^{10}$ A intensa mobilização dos estudantes das escolas, professores e gestores das escolas parceiras no \#ficapibid indica sua viabilidade.

Assim, trabalha-se no sentido de envolver e pesquisar seus "meandros", analisando os planos de aulas e ações realizadas, o protagonismo dos iniciantes docentes (ID) e participação nas feiras científicas e exposições escolares e produção de material didático. Ainda, tem sido analisado o "pensar sobre" o Programa pelos ID, pelas supervisoras e coordenadores, mas igualmente pelos gestores das escolas parceiras e da UFGD, com objetivo de capturar a essência de quem vivenciou e vivencia a experiência de desenvolvimento do PIBID Geografia na UFGD. A realização da pesquisa tem remetido ao contato e diálogo com bolsistas e ex-bolsistas, coordenadores e ex-coordenadores de área, supervisoras e ex-supervisoras, gestores e ex-gestores das escolas e da universidade, desde 2009.

Alguns dados já vêm sendo analisados e sistematizados por meio de planos de trabalho PIVIC ${ }^{11} \mathrm{e}$ PIBIC/CNPq e, inclusive, em função dessas avaliações já se vislumbrou a necessidade de também trazer para dentro da análise, a percepção dos estudantes da escola e também do aluno do curso de Geografia, não participante do PIBID: como o graduando "não-ID" pensa o PIBID?.

Das análises já sistematizadas, no dizer das supervisoras, encontra-se destacado a valorização do magistério. ${ }^{12}$ Há a percepção de que com o PIBID e as possibilidades de outras práticas, mudam seus participantes. (PANIAGUA e SOUZA, 2016, p.15)

Além disso, as supervisoras percebem/apontam que tem havido motivação pela licenciatura, o

\footnotetext{
9 Ver também: GATTI, BARRETO e ANDRÉ (2011).

10 Tem-se acumulado debate acerca da formação de professores, papel do Estágio Supervisionado e o PIBID enquanto possibilidade de formação e universalização. Ver ABREU (2012 e 2013).

11 Trata-se de Relatórios de Pesquisa referentes aos planos PIVIC/UFGD (2015-2016). Respectivamente: RONDIS DE ABREU e ABREU (2016); PANIAGUA e SOUZA (2016).

12 Ver PANIAGUA e SOUZA (2016, p.19).
}

Para0nde!?, Porto Alegre, v.10, n.2, p.56-62, 2018. Edição Especial com artigos publicados originalmente na XII ENANPEGE http://seer.ufrgs.br/paraonde 
que sinaliza que o Programa também contribui para a valorização da profissão de professor(a), condição que também consta como objetivo do PIBID. Uma materialidade que as professoras referenciam pela observação de estudantes que passaram pelas intervenções dos ID e buscaram fazer a licenciatura em Geografia (ou outras) e, inclusive, buscarem o PIBID para participarem quando chegaram na universidade. Sobre essa afirmação das professoras, há evidências no curso de Geografia.

No tocante a formação do professor, da parte dos ID, a pesquisa indica que os acadêmicos do curso de Geografia buscam no PIBID o "aprimoramento na formação". Os dados evidenciam a preocupação com a relação teoria/prática. Os estudantes (70\%) participam do Programa para saírem do contexto apenas de teoria da sala de aula, terem acesso a processos formativos diferenciados e alternativos e se inserirem no contexto da prática docente, dentro da escola. ${ }^{13}$

Da mesma forma, as supervisoras, ao serem indagadas sobre a sua experiência no PIBID, valorizaram a formação proporcionada. Nesse caso, foi destacado o acesso a estudos, leituras e discussões e a formação continuada que esses instrumentos têm proporcionado, inclusive com referência a ingresso em pós-graduação, mas principalmente as possibilidades de acesso a novas metodologias e tecnologias, a importância de voltar a ter contato com a universidade e de perceberem que os estudantes da escola mudam a partir da participação nas intervenções dos iniciantes docentes ID), assim como mudam e se qualificam os próprios ID - "pibidianos".

Para os ID, a permanência por um tempo no PIBID tem facilitado a realização dos estágios obrigatórios, sobretudo a elaboração das atividades de planejamento e realização da regência, de modo a se diferenciarem, ainda que não explicitamente, pela experiência no Programa.

A pesquisa com base em entrevistas com ID e com as supervisoras tem demonstrado a valorização da oportunidade de formação e os desafios decorrentes dessa experiência.

A "palavra aberta" dada às professoras para expressarem-se livremente sobre o PIBID demonstra que a contribuição com a formação continuada, a motivação para a reflexão da prática e uso de novas metodologias são elementos de qualificação do Programa, assim como compareceu a preocupação com a manutenção do PIBID, de um lado, e a demanda pela sua ampliação, de outro lado.

No caso dos iniciantes docentes, na mesma condição de "palavra aberta" de expressão de ideias, o destaque apresentado foi: mudança de postura frente à licenciatura e a valorização da profissão; qualificação da formação construída entre os meandros dos estudos e das práticas; contato com os estudantes e professoras nas escolas e a percepção de aproximação entre a escola e a universidade; valorização e reconhecimento do Programa, como política de formação de professores e demanda por ampliação do PIBID, no número de participantes e nos valores de bolsas. Foi recorrente a preocupação com a possibilidade de extinção do Programa, seja pelas supervisoras, seja para os ID.

\section{Algumas considerações conclusivas ...}

Retomamos a pergunta: Em que medida o PIBID de Geografia tem respondido a essas condições e expectativas?

Do ponto de vista do discurso dos iniciantes docentes e das supervisoras, é possível dizer que o PIBID de Geografia responde às expectativas e desafios propostos pelo Programa, enquanto política instituída. Ao mesmo tempo, também comparece a percepção de que o PIBID tem contribuído com expectativas de formação colocadas para a escola, para além dos compromissos da política.

Se a informação e informatização chegou com o século XXI como desafio, no âmbito da escola, da universidade e do cotidiano de alunos e professores, a democracia e os direitos conquistados na sociedade moderna, na primeira década do novo século, colocam à escola e ao professor temáticas desafiadoras: igualdade e respeito à diversidade étnica, racial, de deficientes físicos, homossexuais, de gênero e cuidado com meio ambiente. "Tudo isso implica em novos conceitos culturais e práticas no interior da escola e também no interior dos cursos de formação docente." (ABREU e SOUZA, 2016, p.550)

Observa-se que as escolas participantes do PIBID Geografia/UFGD e as professoras supervisoras, vislumbram nos bolsistas e no Programa, potencialidades de realização de trabalhos que venham

13 RONDIS DE ABREU e ABREU (2016, p.12/3).

ParaOnde!?, Porto Alegre, v.10, n.2, p.56-62, 2018. Edição Especial com artigos publicados originalmente na XII ENANPEGE http://seer.ufrgs.br/paraonde 
responder a essas temáticas. Não é aleatório que trabalhos sobre diversidade étnico-racial, educação ambiental, educação no trânsito, respeito à vida, eleições, copa do mundo, desigualdades sociais, crise hídrica, direito a cidade venham comparecendo como "tarefas" a serem trabalhadas como temas transversais pelos participantes do PIBID, nas escolas da educação básica.

Observam-se trocas significativas que perpassam todos os segmentos envolvidos, da escola à universidade. Contudo, ainda há muitas questões a fazer, materiais desenvolvidos/produzidos a analisar, numa condição que envolve levantamentos e análises em andamento e ainda por começar.

Também remete a própria capacidade de organização e materialidade dos trabalhos executados, planejado para ser em $b \log ^{14}$, mas que tem esbarrado na dificuldade de manutenção e periodicidade, sobretudo porque domínio das mídias ainda é um problema na escola e na universidade. Nesse sentido, o PIBID Geografia carece de promover a divulgação e transparência de todas suas atividades.

Há que se avançar ainda para analisar a capacidade do Programa qualificar o trabalho nas escolas. Estamos levantando as percepções dos estudantes, além disso, ainda há que se analisar essa condição no curso de Geografia da UFGD, a partir do levantamento de monografias, dissertações e teses, mas também trabalhos e artigos publicados envolvendo o PIBID Geografia/UFGD.

Condições que em seu conjunto contribuirá para análise e desvelamento das contradições inerentes aos processos e que tem colocado o PIBID na perspectiva de avanços na construção de cumplicidade na formação de sujeitos para a sociedade e para a vida (inclusive, o trabalho), seja na escola, seja na universidade.

\section{Referências}

ABREU, S. "Formação de professor de Geografia: construindo conhecimento, consolidando práticas. Aspectos da relação ensino-aprendizagem" In: ANDRES, J. FRANCISCHERT, M. N. e AGUIAR, W. G. Ensino de Geografia: abordagens sobre representações geocartográficas e formação do professor. Cascavel-PR: Edunoeste, 2012, p. 11/48.

ABREU, S. "O estágio supervisionado na formação dos professores de Geografia: diálogos ininterruptos" In: ALBUQUERQUE, M. A. M e FERREIRA J. A. S. (org.). Formação, pesquisa e práticas docentes: reformas curriculares em questão. João Pessoa (PR) : Editora Mídia, 2013, p.87-104.

ABREU, S. e SOUZA, A.O. "O Programa institucional de Bolsa de Iniciação à Docência (PIBID) do curso de Geografia/UFGD: linguagens, prática e formação de professores. Rio de Janeiro : GEO UERJ, no 29, 2016, p.543-565.

BOITO JR, Armando. "As bases políticas do neodesenvolvimetismo". Disponível em: http://bibliotecadigital.fgv.br/dspace/bitstream/handle/10438/16866/Painel\%203\%20\%20Novo\%20Desenv\%20BR\%20-\%20Boito\%20-\%20Bases $\% 20$ Pol\%20Neodesenv\%20$\%$ 20PAPER.pdf?sequence $=1$

BRASIL. CAPES. Programa Institucional de Bolsas de Iniciação Docência, 2008. http://www.capes.gov.br/educacao-basica/capespibid

BRASIL. Presidência da República. Lei no 13.005, de 25 de junho de 2014. Aprova o Plano Nacional de Educação - PNE e dá outras providências. Brasília : Casa Civil. Disponível em: http://www.planalto.gov.br/ccivil 03/ ato2011-2014/2014/lei/l13005.htm.

DINIZ, E. "Desenvolvimento e Estado Desenvolvimentista: tensões e desafios da construção de um novo modelo para o Brasil do século XXI" In: Revista de Sociologia e Política. V.21, no4, set. 2013, p.9-21.

14 O blog de Geografia foi criado, contudo não houve continuidade em sua alimentação com os materiais produzidos, seja pelo volume de atividade que tem os coordenadores de área e que não dão conta de realizar também essa tarefa, seja porque não têm habilidade para fazê-la, ou ainda, porque há rotatividade dos sujeitos e não necessariamente há o repasse do conhecimento para garantir a alimentação e divulgação da totalidade de atividades já desenvolvidas. Aspectos da organização do projeto que dificultam a realização da pesquisa. É mister registrar a existência de dois grupos de Facebook, mesmo que fechados, que tem permitido pelo menos o acesso a parte significativa de atividades desenvolvidas. Além de um terceiro grupo criado (em 2017) aberto, mas com restrição a publicação de terceiros, em uma tentativa de unir as publicações dos dois grupos do subprojeto Geografia.

ParaOnde!?, Porto Alegre, v.10, n.2, p.56-62, 2018. Edição Especial com artigos publicados originalmente na XII ENANPEGE http://seer.ufrgs.br/paraonde 
FONSECA, P.C.D. "Desenvolvimentismo: a construção do conceito" In: Texto para discussão" no2103. Brasília : IPEA, julho 2015.

GATTI, B.A.; ANDRÉ, M.E.D.A.; GIMENEZ, N.A.S. e FERRAGUT, L. Um estudo avaliativo do Programa Institucional de Bolsa de Iniciação à Docência (PIBID). GATTI, B.A.; ANDRÉ, Marli, E.D.A.; GIMENEZ, N.A.S. e FERRAGUT, L. (Pesquisadores). São Paulo: FCC/SEP, 2014.

GATTI, B.A.; BARRETO, E.S.S. e ANDRÉ, M.E.A. Políticas recentes no Brasil - Um Estado da Arte. Brasília : UNESCO, setembro 2011.

OLIVEIRA, T. B. 0 Golpe de 2016: Breve ensaio de História Imediata sobre democracia e autoritarismo. Historiæ, Rio Grande, 7 (2): 191-231, 2016.

PANIAGUA, L. F. O. e SOUZA, A.O. “O PIBID de Geografia/UFGD como perspectiva de qualificação da educação básica, sob os olhares críticas das professoras supervisoras: a incorporação de novas linguagens na relação ensino-aprendizagem no cotidiano escolar" Dourados : UFGD. (Relatório Final de Iniciação Científica", 2016).

PRONER, C. et. al. A resistência ao Golpe de 2016. 1a Edição. Bauru/SP: CANAL 6 editora, 2016. RONDIS DE ABREU, L.N. e ABREU, S. O PIBID de Geografia da UFGD como política de formação de professores e a experiência dos acadêmicos de geografia (2009-2015). Discurso e Prática. Dourados : UFGD. (Relatório Final de Iniciação Científica”, 2016).

SOCZEK, D. "PIBID como Formação de Professores: reflexões e considerações preliminares" In: Formação Docente - Revista Brasileira de Pesquisa sobre Formação de Professores. Anped. Autêntica Editora. Volume 03/no 05 ago-dez, 2011.

https://www.pensaraeducacaoempauta.com/da-formacao-de-professores-06-5-16 